using routine methods and analysed after trypsin $G$ banding. In addition, lymphocytes were cultured with BrdU in order to demonstrate the late replicating $\mathrm{X}$ chromosome.

Both parents had normal karyotypes, but the proband's karyotype revealed an apparently balanced X;13 translocation: 46,X,t $(X ; 13)$ (Xpter $\rightarrow$ Xq13::13p11 $\rightarrow$ 13pter;13qter $\rightarrow 13 p 11:: X q 13 \rightarrow X q$ Xer) (figure). BrdU incorporation showed the normal $X$ to be late labelling in all of 100 cells examined. As the normal $X$ was late replicating in each cell, it was not possible to detect any spread of inactivation from the $X$ to the 13 in the 100 cells examined.

\section{Discussion}

Although it is easy to see why unbalanced $\mathrm{X}$; autosome translocations cause phenotypic abnormalities due to deletion or duplication of chromosomal material, carriers of balanced translocations are often phenotypically normal. However, there are several well established classes of abnormality found in association with $\mathrm{X}$;autosome translocations. Firstly, ovarian dysgenesis is associated with breakpoints on the $\mathrm{X}$ within the region $\mathrm{Xq13}$ and $\mathrm{Xq} 26{ }^{2}$ Secondly, evidence is accumulating that there can be mutation damage by gene disruption at the breakpoint on the $\mathrm{X}$ chromosome. Examples supporting this theory include the cases of Duchenne muscular dystrophy occurring in girls with de novo $X$; autosome translocations with breakpoints at or near Xp21 (listed in Hodgson and Bobrow ${ }^{3}$ ), corresponding to the position allocated to the DMD locus by linkage analysis. ${ }^{4}$

Thirdly, the position effect can cause phenotypic abnormalities in balanced $X$;autosome translocations, due to dissociation of genes from regulator sites or the spread of inactivation from an area of heterochromatin to a portion of the neighbouring translocated chromosome which would not normally be inactivated.

Five of seven previously reported patients with $X$; autosome translocations with breakpoints at $\mathrm{Xq}^{2}{ }^{2}$ were infertile, but none had other dysmorphic features. Of seven patients reported with deletions of $\mathrm{Xq}$ with breakpoints at Xq13, none had phenotypic abnormalities other than the Turner stigmata. ${ }^{5}$ Our patient is thus the first reported case of a balanced $\mathrm{X}$; autosome translocation with a breakpoint at Xq13 and an abnormal phenotype, other than gonadal dysgenesis.

\footnotetext{
References

1 Scheres JMJC, Merkx GFM, Hustinx TWJ. Prometaphase banding of human chromosomes with basic fuchsin. Hum Genet 1982;61:8-11.

2 Madan K. Balanced structural changes involving the human X: effect on sexual phenotype. Hum Genet 1983;63:216-21.

${ }^{3}$ Hodgson SV, Bobrow M. Two cases of an X/autosome translocation in females with incontinentia pigmenti. Hum Genet 1985;71:231-4.

4 Murray JM, Davies K, Harper PS, Meredith L, Mueller CR, Williamson R. Linkage relationship of a cloned DNA sequence on the short arm of the $\mathrm{X}$ chromosome to Duchenne muscular dystrophy. Nature 1982;300:69-71.

Skibsted L, West H, Niebuhr E. X long-arm deletions. A review of non-mosaic cases studied with banding techniques. Hum Genet 1984;67:1-5.
}

Correspondence and requests for reprints to Dr S V Hodgson, Paediatric Research Unit, Guy's Hospital Medical School, Guy's Tower, London SE1 9RT.

\title{
Terminal deletion of the long arm of chromosome 10
}

\section{HAZEL CURTIS*, R T HOWELL $\dagger$, AND CELIA COPE $\dagger$ \\ ${ }^{*}$ Royal Devon and Exeter Hospital, Wonford, Exeter EX2 5DW; and tSW Regional Cytogenetics Centre, Southmead Hospital, Bristol BS10 5NB.}

SUMmARY A de novo chromosome abnormality interpreted as a terminal deletion of chromosome $10, \operatorname{del}(10)(\mathrm{pter} \rightarrow \mathrm{q} 25 \cdot 2:)$, was ascertained in a newborn female with multiple malformations. The clinical features observed at birth and on follow up at 10 months of age

Received for publication 20 September 1985. Accepted for publication 24 September 1985. are described and compared with previously reported cases.

Three patients with monosomy for the chromosome region $10 \mathrm{q} 25 \rightarrow \mathrm{qter}$ have been described previously, two with a de novo terminal deletion ${ }^{12}$ and one with an unbalanced familial translocation. ${ }^{3}$ In addition, five reports describe slightly more distal deletions with the breakpoint in band $10 \mathrm{q} 26,{ }^{4-8}$ and a single 


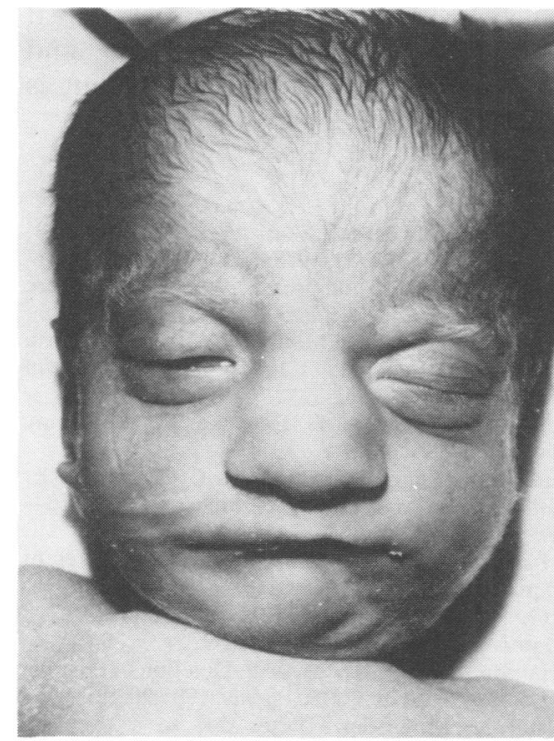

(a)

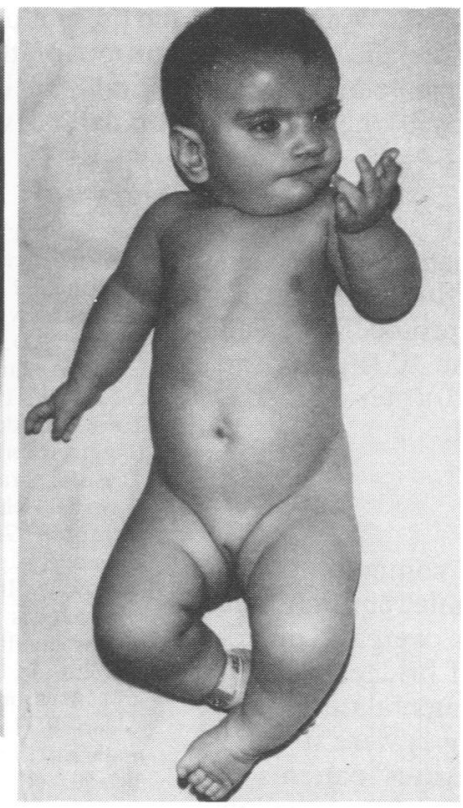

(b)
FIG 1 The patient (a) at birth and (b) at 10 months of age. report describes monosomy for the region 10 q23 $\rightarrow$ qter. $^{9}$

\section{Case report}

The proband (fig 1a) was the first child of unrelated parents aged 18 and 19 years, born by normal vaginal delivery at 42 weeks' gestation after induction of labour. At birth she was covered with vernix and was noted to be below the 3rd centile for all parameters: occipitofrontal diameter $30.5 \mathrm{~cm}$, weight $2.15 \mathrm{~kg}$, length $44 \mathrm{~cm}$. She had microcephaly and brachycephaly. The eyes were prominent owing to shallow orbits and there was marked conjunctivitis. The mandibles were hypoplastic (right more than left), the nose was large and broad with a prominent bridge, and the ears were large but not low set. A unilateral simian crease and bilateral clinodactyly were noted, as well as severe bilateral talipes equinovarus. She had hypoplastic female external genitalia. There was no evidence of cardiac anomalies. A skeletal survey confirmed microcephaly and revealed small facial bones, particularly in the mid-face. Twelve pairs of ribs were present with splaying of the lower ones. The long bones were gracile in the mid-portion with some linear layering sclerosis.

At 10 months of age (fig 1 b) her development was

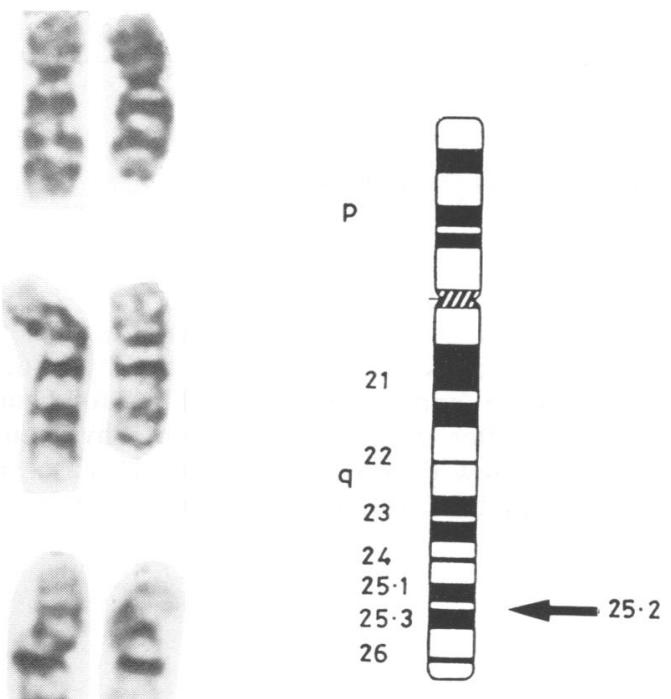

FIG $2 G$ banded homologues of chromosome 10 from three cells, the abnormal chromosome to the right, and a diagrammatic representation indicating the breakpoint (arrowed). 
severely delayed (less than 3 months), Weight and length remained below the 3rd centile and the head circumference was only $38.5 \mathrm{~cm}, 2 \mathrm{~cm}$ below the $3 \mathrm{rd}$ centile. Feeding was predominantly by nasogastric tube.

\section{CYTOGENETIC STUDIES}

Chromosome analysis was performed on a specimen of peripheral blood obtained shortly after birth. G banding using a trypsin-Leishman protocol revealed a terminal deletion of chromosome 10 (fig 2). The karyotype was thus $46, \mathrm{XX}, \operatorname{del}(10)(\mathrm{pter} \rightarrow \mathrm{q} 25 \cdot 2:$ ). Parental karyotypes were normal.

\section{Discussion}

Clinical features of the patient common to the majority of earlier cases with a similar chromosome abnormality included low birth weight, microcephaly, a broad prominent nasal bridge, large or otherwise abnormal ears, developmental delay, and growth retardation. ${ }^{8}$ Her facies (fig 1) were strongly reminiscent of some of the previous patients, ${ }^{2}$ although prominent eyes resulting from shallow orbits have not been apparent previously and hypoplasia of the mandibles is not a consistent feature.

So far there is an excess of females (9/12 including the present patient) with monosomy for the terminal portion of the long arm of chromosome 10 , and overall the clinical presentation of this patient is compatible with those previously reported.

\section{References}

1 Lewandowski RG, Kukolich MK, Sears JW, Mankinen CB. Partial deletion 10q. Hum Genet 1978;42:339-43.

2 Mulcahy MT, Pemberton PJ, Thompson F, Watson M. Is there a monosomy 10qter syndrome? Clin Genet 1982;21:33-5.

3 Wegner RD, Kunze J, Paust H. Monosomy 10qter due to a balanced familial translocation: $\mathrm{t}(10 ; 16)(\mathrm{q} 25 \cdot 2 ; \mathrm{q} 24)$. Clin Genet 1981;19:130-3.

4 Turleau C, de Grouchy J, Powset G, Bauygues D. Monosomy 10qter. Hum Genet 1979;47:233-7.

5 Taysi K, Strauss AW, Yang V, Padmalatha C, Marshall RE. Terminal deletion of the long arm of chromosome 10: q26qter. Ann Genet (Paris) 1982;25:141-4.

6 Zatterale A, Pagano L, Fioretti G, et al. Clinical features of monosomy 10qter. Ann Genet (Paris) 1983;26:106-8.

7 Evans-Jones G, Walker S, Howard PJ. A further case of monosomy 10qter. Clin Genet 1983;24:216-9.

8 Shapiro SD, Hansen KL, Pasztor LM, et al. Deletion of the long arm of chromosome 10. Am J Med Genet 1985;20:181-96.

9 Chieri P, Iolster N. Monosomy 10qter due to a balanced maternal translocation: $\mathrm{t}(10 ; 8)(\mathrm{q} 23 ; \mathrm{p} 23)$. Clin Genet 1983;4: 147-50.

Correspondence and requests for reprints to $\mathrm{Dr} \mathrm{H}$ Curtis, Department of Child Health, Royal Devon and Exeter Hospital (Wonford), Exeter EX2 5DW.

\section{Announcement}

\section{CLINICAL GENETICS SOCIETY}

The next meeting of the Clinical Genetics Society will be held at the Royal College of Physicians, London, on 5 and 6 December 1986 following immediately after the Royal College of Physicians' Conference 'New Prospects in Genetic Disease' on 3 and 4 December 1986 . Those intending to present papers or posters at the Clinical Genetics Society meeting should submit abstracts (about 150 words) before 17 October 1986 to the Secretary of the Society, Professor N C Nevin, Department of Medical Genetics, Institute of Clinical Science, Grosvenor Road, Belfast BT12 6BJ, Northern Ireland, from whom forms are available on request. 